\title{
When coercion meets hope: Can forensic psychiatry adopt the recovery model?
}

\author{
SZ Kaliski, HG de Clercq
}

Forensic Mental Health Services, Department of Psychiatry and Mental Health, University of Cape Town, South Africa

Forensic patients are generally unwilling participants in their own rehabilitation. Worse still, their treating clinicians, in addition to managing their disorders and preparing for their reintegration into the community, are also beholden to the courts (and therefore the community at large) to ensure that the risk they pose to others is eliminated. Discharge, by a judge-in-chambers, will only be granted if the patient has clinically recovered from his mental illness, has addressed the purported risk factors that contributed to his offending (such as alcohol and substance abuse), has an identified family member (or acceptable substitute) who will supervise him for a parole period, and will be compliant with treatment. This combination of requirements proves to be an insurmountable obstacle for most, due to their varying degrees of ongoing psychopathology, uncertain risk for recidivism and the impoverished, sometimes chaotic, conditions of their social circumstances. Not surprisingly many become demoralised, listlessly participate in therapeutic programmes, openly flout rules, and only pursue constricted goals, such as being granted ground parole and obtaining small quantities of tobacco (or dagga). They lack hope, which actually ought to be a vital component of their rehabilitation.

\section{What ails forensic psychiatry programmes?}

Most forensic mental health programmes focus primarily on treating patients' mental illness in much the same way that all psychiatric patients are managed. ${ }^{2}$ Risk management is usually presumed to have been accomplished when the patient achieves clinical recovery, which really means remission of illness and compliance with treatment. ${ }^{3}$ Not all patients require equal measures of risk management and psychiatric care, nor has it been possible to pursue both seamlessly as part of an overall treatment philosophy, although both seem to involve paternalistic care. ${ }^{4}$
There is a dearth of research into specialised programmes that address the specific needs of forensic patients, and it has been estimated that probably less than $10 \%$ of articles in forensic journals deal with treatment issues. ${ }^{1}$ Therefore it is not really known whether so-called criminogenic factors are ameliorated by response to medication, psychotherapy, occupational therapy, good nursing, or just the admission per se. ${ }^{5}$ Taking personal responsibility and coming to terms with the reality of their offences, sometimes called "offender recovery", only seems to work in a handful of patients. Offences are often denied in conscious or unconscious ways, and many may use their psychosis as a defence for their criminal behaviour. ${ }^{4}$

Forensic rehabilitation is a lengthy process, during which the multidisciplinary team forms long-term therapeutic alliances with their patients, quite unlike that in the general psychiatric system, where there is a high turnover of patients who are admitted for brief periods, and whose contact with a multidisciplinary team is usually fragmented.

Another unacknowledged difficulty is that the members of the multidisciplinary team (MDT) may subscribe to differing paradigms, which may create tensions, and occasionally result in divergent management plans. ${ }^{1}$ As patients progress through the forensic system they also may find themselves under the care of different MDT's, who may have encountered them during a previous cycle of rehabilitation, and may have formed hardened negative prejudices. $^{4}$

\section{The failure of the risk assessment enterprise}

During the 1990's the fervent debate over whether serious psychiatric disorders were associated with an increased risk of violent behaviour eventually resolved into a qualified yes. ${ }^{6 ; 7}$ But clinicians' ability to predict dangerousness was regarded as almost hopeless, which led to intensive research into the development of actuarial tools that objectively evaluated predetermined risk factors, and thereby apparently provided an assessment of the degree of risk any individual posed. This promise has not been 
realised for myriad reasons. Regardless of tool or method used no current risk assessment can offer adequate levels of accuracy, long-term predictions, or properly take into account contextual and social factors. ${ }^{8}$ This is not good enough for forensic practice, where patients have to be discharged, or sent on long leaves, supposedly with the assurance that longterm predictions about their behaviour will be valid.

Most forensic mental health rehabilitation programmes continue to regard long-term risk assessment as one of their bedrock responsibilities, 'to keep the community safe'. Consequently very few forensic patients are discharged, many are granted only limited periods of leave, and the service is bursting with an expanding inpatient population, because clinicians have resorted to being overcautious in the face of their inability to trust the future.

This combination of the demand to contain risk with the realisation that risk cannot really be assessed for appreciable periods has led to clinicians exercising inordinate control over the movements of forensic patients. Somehow patients are not quite responsible for their antisocial actions anymore, as it now the clinicians' fault for (recklessly) allowing them freedom.

\section{What is the Recovery Model?}

The medical model primarily aims to achieve clinical recovery, namely cure or remission of illness, or if that is not possible, long-term symptom control or amelioration. ${ }^{3}$ Unfortunately both of these approaches involve control by the treating clinician as to what can be regarded as an acceptable outcome. Psychiatrists have long laboured under the delusion that effective biological treatments are imminent, and are now perhaps a little confused that so many of their patients do not improve measurably despite their best prescribing efforts and psychotherapeutic interventions. Treatment-resistance, which is relatively common, is regarded as a frustrating clinical phenomenon that demoralises both doctor and patient, and too often leads to pejorative responses.

The realisation that people with chronic illnesses need to experience hope and to feel somewhat in control of their lives has led to the development of the concept of 'personal recovery'. This approach recognises that many have to optimise their lives despite their ongoing disabilities. . $^{3 ; 9}$ Therefore treatment decisions should be made in collaboration with patients, taking into account their personal circumstances, aspirations, cultural, religious, ethnic, or any other important factors. The aim is to promote wellness and resilience, as well as providing necessary medical and psychotherapeutic care. Central to personal recovery is the acceptance by clinicians that they are working in partnerships with their patients who are not compelled to accept their directives. This implies that patients are presented with choices, followed by negotiations that lead to agreement. Nevertheless, this can be difficult when patients are detained against their will, and their array of available choices small. ${ }^{10}$

Nevertheless, every effort has to be made to liaise with other agencies and professionals so that they can achieve personal development. Essentially mental health programmes that adopt this model have to change their treatment philosophy, which really involves questioning the traditional paternalistic approach.

\section{Can the Recovery Model be accommodated in forensic mental health practice?}

There are many obstacles to applying the recovery model in forensic settings, which compromises forensic patients' ability to participate in their own rehabilitation, and more importantly to exercise choice. Forensic patients are usually admitted to high secure facilities for extended periods, often are too disordered and behaviourally disturbed (which requires control) to engage appropriately with the MDT, and even when well, are indignant at being labelled as mentally ill and bad. ${ }^{4 ; 11}$ Most of our patients derive from deprived and chaotic psychosocial circumstances that cannot be changed. Many committed their offences against family members, who now have to be persuaded to participate in their rehabilitation. And commonly, patients often have to be re-admitted (maybe for the umpteenth time) after relapsing and behaving aggressively at home while on leave, which leaves everyone feeling dispirited (and sometimes angry). They eventually lack motivation to actively pursue meaningful pursuits, which may result in failure to take on important roles in life, such as parenting or partnering, or any activities that could promote health and resilience, such lifestyle changes or abstinence from substances. ${ }^{3}$

Despite these constraints forensic mental health can adopt the recovery model, and thereby jettison its paternalistic practices. The first step is to change the treatment philosophy. Members of the MDT should convey to their patients consistently that they are collaborating with them, that despite setbacks and a fluctuating need for the clinicians to assume control, there is hope that the patients will regain control and be able to exercise choices. Even when the patients are in maximum secure facilities they can be engaged collaboratively, by discussing their disorder, needed treatment and, most importantly, to negotiate plans that are optimistic and hopeful. This often helps patients accept their stay in high secure facilities as time-out in a sanctuary, and to prepare for the next phase. Currently forensic patients too frequently view their admissions as punishment, and not an opportunity to develop personally. ${ }^{5}$ Detention could then be experienced as providing an opportunity for recovery that would otherwise not exist in the community. Sometimes change or achieving personal meaning can only occur when people are faced with crises or life changing events (such as incarceration or hospitalisation).

A helpful approach is the 'stage progressive recovery model', in which patients are engaged in phases in developing their life skills (which includes self care, self control, interpersonal skills, socialization, relapse prevention), coping skills, and ultimately achieving independent living with a job. ${ }^{12}$ Throughout their admission patients are provided with hope that whatever their disability plans are being formulated to optimise their lives. Most patients will be long term residents, but they can be given some meaningful autonomy. For example, occupational therapy builds self esteem by addressing life skills, improving the use of time, and ultimately offering the promise of supported employment in the open labour market, even though the patient may have to remain in hospital. Simultaneously, social work and psychological 
interventions can restore important relationships with family and community.

Perhaps the most important consequence would be that forensic MDT's would be more willing to use creative risk assessment. Instead of resolutely insisting that 'dangerous' patients remain locked up and restricted, clinicians could be more willing to trust their patients and take reasonable chances, and as the MDT forms positive therapeutic alliances with them it then becomes possible to set up mutually agreed upon ways of monitoring risk. The fact that patients remain psychotic, live in a remote place, or have other difficult to solve problems can be incorporated into a plan that tries to make the most of their situations. For example, patients can attend courses from the hospital, agree to allow their family members to alert the team when they abuse substances, or perhaps get assistance in interacting with their employers. At every step the patient feels supported as a partner, and not as a subjugated prisoner.

\section{Some caveats...}

There is currently little research into outcomes based on the recovery model, although there is some evidence that forensic assertive community treatment programmes do succeed in keeping discharged patients for appreciable periods in the community. ${ }^{12}$ But these were small selected groups. Most forensic patients have co-morbid disorders, such as substance abuse and personality disorders, and may not respond to a collaborative approach. There always are patients who are able to exploit the best intentions of others and split the members of MDT's, which sometimes explains why they are in the system in the first place.

Nevertheless, forensic mental health programmes should adopt the recovery model, first as a philosophy, then as a means of optimising the lives of those who have to overcome a multiplicity of difficulties while remaining resident in the service for lengthy periods.

\section{Reference}

1. Hillbrand $K$, Young JL. Instilling hope into forensic treatment: The antidote to despair and desperation. Journal of the American Academy of Psychiatry and the Law 2008; 36:90-94.

2. Robertson P, Barnao M, Ward T. Rehabilitation frameworks in forensic mental health. Aggression and Violent Behaviour 2011; 16:472-484.

3. Barber ME. Recovery as the new medical model for psychiatry. Psychiatr Serv 2012; 63(3):277-279.

4. Drennan G, Alred D. Secure recovery: Approaches to recovery in forensic mental health settings. London: Routledge, 2012.

5. Lindqvist P, Skipworth J. Evidence-based rehabilitation in forensic psychiatry. Br J Psychiatry 2000; 176(4):320-323.

6. Arseneault L, Moffitt TE, Caspi A, Taylor PJ, Silva PA. Mental disorders and violence in a total birth cohort. Archives of General Psychiatry 2000; 57:979-986.

7. Swartz.M.S., Swanson JW, Hiday VA, Borum R, Wagner R, Burns BJ. Violence and severe mental illness: The effects of substance abuse and nonadherence to medication. Am J Psychiatry 1998; 155(2):226-231

8. Yang $M$, Wong SCP, Coid J. The efficacy of violence prediction: $A$ meta-analytic comparison of nine risk assessment tools. Psychological Bulletin 2010; 136(5):740-767.

9. Royal College of Psychiatry. A common purpose: Recovery in future mental health services. 2007. London, Social Care Institute for Excellence.

10. Roberts G, Dorkins E, Wooldridge J, Hewis E. Detained - what's my choice? Part 1: Discussion. Advances in Psychiatric Treatment 2008; 14:172-180.

11. Mezey GC, Kavuma M, Turton P, Demetriou A, Wright C. Perceptions, experiences and meanings of recovery in forensic psychiatric patients. The Journal of Forensic Psychiatry \& Psychology 2010; 21 (5):683-696.

12. Smith RJ, Jennings JL, Cimino A. Forensic continuum of care with Assertive Community Treatment (ACT) for persons recovering from co-occurring disabilities: Long-term outcomes. Psychiatric Rehabilitation Journal 2010; 33(3):207-218.

\section{INSTRUCTIONS FOR AUTHORS African Journal of Psychiatry (AJP)}

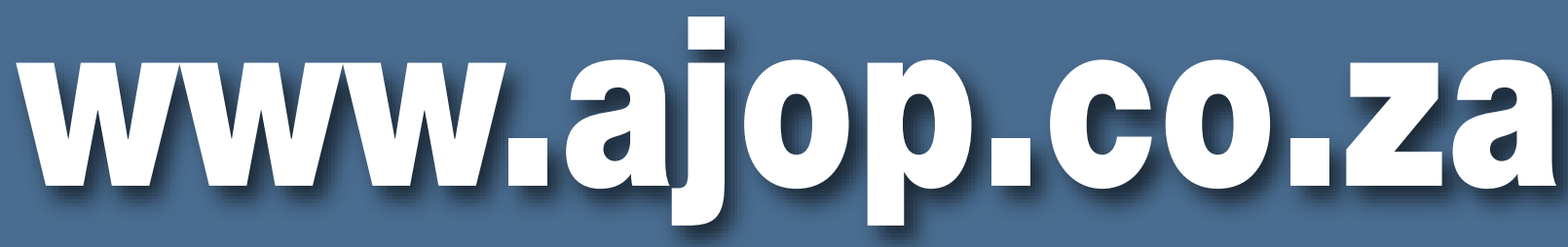

All manuscripts and correspondence should be emailed to:

Professor CP Szabo,

email: christopher.szabo@wits.ac.za 